\title{
Patterns of Associated Injuries in Patients with Mild/Moderate Head Injuries
}

\author{
Olubunmi Emmanuel Odeyemi ${ }^{1 *}$, Chiamaka Bianca Offorbuike ${ }^{1,2}$, Oluwasegun Eniayekan ${ }^{1,2}$, \\ Eniola Olusanya ${ }^{1,2}$, Shekinah Yobuh Williams ${ }^{1,2}$, Salau Hikmat Moromoke ${ }^{1,2}$, \\ Oluwadamilola Adeola Adeniyi ${ }^{1,2}$, Suliyat Olawuwo ${ }^{1,2}$, Abiodun Akintayo ${ }^{1,2}$, Samuel Olawale ${ }^{1,2}$, \\ Chinweoge Epum ${ }^{1,2}$, Jesujuwon Olawuyi ${ }^{1,2}$, Philip Alabi ${ }^{1,2}$, Lordstrong Akano ${ }^{1,2}$
}

${ }^{1}$ College of Medicine, University of Ibadan, Ibadan, NIGERIA

${ }^{2}$ College Research and Innovation Hub, Ibadan, NIGERIA

* Corresponding author: emmabunmite@gmail.com

\section{EUROPEAN JOURNAL OF BASIC MEDICAL SCIENCE}

Eur J Basic Med Sci 2020;10(1):3-10

Received: 22 Aug 2020

Accepted: 3 Oct 2020

\begin{abstract}
Traumatic Brain Injuries (TBI) or head injuries are injuries or trauma to the scalp and or brain caused by an outside force, usually a violent blow or collision to the head by accident or deliberate attack. It can also be called be craniocerebral trauma. TBI are examples of acquired, non-degenerative assault to the brain from an external mechanical force, causing impairment of brain functions, with or without alteration to the mental state or consciousness of the victim. This paper provides a synopsis of the epidemiology and patterns of associated injuries in mild and moderate head injuries in literature. Mild and moderate head injuries were selected because they are by far commoner than severe head injuries and the outcomes are widely varied than severe head injuries. Traumatic brain injury is a global and public health problem, which in the coming years, might be the leading cause of death in Africa. High incidence is found among the adolescent and the adult age group and gender-wise, it is common among the males of the same age group. Likewise, the provision of an ambulance system and standard healthcare facilities to manage 18 patients with a traumatic brain injury can not be overemphasized.
\end{abstract}

Keywords: head injuries, trauma, traumatic brain injuries 


\section{INTRODUCTION}

Traumatic Brain Injuries (TBI) or head injuries are injuries or trauma to the scalp and or brain caused by an outside force, usually a violent blow or collision to the head by accident or deliberate attack. It can also be called be craniocerebral trauma [1]. TBI are examples of acquired, non-degenerative assault to the brain from an external mechanical force, causing impairment of brain functions, with or without alteration to the mental state or consciousness of the victim [2]. A comprehensive global study estimated that about 69 million new cases of TBI will occur globally every year, with mild injuries being by far the commonest (81\%) at 10 times more than the incidence of moderate and severe TBI combined [3].

Many times, head injuries occur with significant associated injuries, especially in poly-traumatized patients [4], which worsens the outcome and prognosis. Some of the reported associated injuries include maxillofacial, spine, chest, abdominal, limb, and eye injuries, among others [5].

Head injury is an important public health problem and of great economic significance, as it typically affects the economically active age group. A study of head injury in motorcyclists revealed that over $70 \%$ of the patients were between the ages of 15 and 44 years [5]. This has far-reaching impacts on the economy if not paid attention to.

Head injuries in patients have been labeled as a "silent epidemic" affecting both the developed and the developing nations [6].

In a study conducted by Punchak et al. on the mechanism of Paediatric TBI, it was reported that the mean age in this age group was 7.5 years with male preponderance and majorly pedestrian road traffic injuries (RTIs). Likewise, fall is commoner in the age group 3-9 years. It was also observed that the majority of these pediatric patients were young unsupervised pedestrians and therefore enjoined parents and guardians to stay alert for the safety of their wards [7].

According to "WHO Global Status Report on Road Safety", more than 1.2 million people die on the world's roads every year and as many as 50 million others are injured [8]. Especially in low- and middleincome countries, road traffic injuries remain a serious health problem.
In a prospective study conducted by Wong et al., it was hypothesized that TBI will be the leading cause of death in Africa from 2050 especially in the eastern and western regions and the estimated counts are highest in male youth between 15 to 34 years. These estimates were accepted because of the socio-economic and impoverished nature of the setting especially as evident in the lack of adequate pre-hospital, hospital, and posthospital care with poor road networks [9].

This paper provides a synopsis of the epidemiology and patterns of associated injuries in mild and moderate head injuries in literature. Mild and moderate head injuries were selected because they are by far commoner than severe head injuries and the outcomes are widely varied than severe head injuries [3]. Associated injuries in head-injured patients increase the injury severity score and worsen prognosis, hence the focus of this paper [5].

\section{EPIDEMIOLOGY}

There has been a significant rise in head injury cases in developing countries, especially in the African continent. This has been attributed to the increase of cars and motorcycles on the roads [9], non-compliance of motorcyclists to the use of helmet, bad roads, and non-efficient traffic systems in most African countries. As a result of poor handling and registration of data seen in Low and Middle-Income Countries (LMIC), there seems to be a paucity of data on head injury cases in Africa.

However, the World Health Organization (WHO) estimated that head injuries will be the third leading cause of death by 2020 [10]. In most studies done in Africa, there was a higher male: female ratio ( $M$ : $F)$. Adeleye et a.,l in Lagos, Nigeria showed a male: female ratio of 5.8:1 [11]. A study done in Ilorin, Nigeria showed that most of their patients fell under the age category of 15-44 years [5]. Khanabhai et al expressed in their study that the majority of their patients were under the category of 20-29 [12]. These pieces of evidence emphasize the economic implications of head injury due to a preponderance amongst the economically active population.

The etiology of traumatic brain injuries varies across the different age groups. Overall, road traffic accidents remain the most common cause of TBI [11,13-16], with motorcycle accidents accounting for most cases in Africa and developing countries $[16,17]$. Falls were also reported as the most common cause of TBI in the 
elderly population [14]. TBI from sporting activities and other causes account for the least in most age groups [18].

\section{Patterns of Injuries Associated with Mild/Moderate Head Injuries}

There are four types of injuries were associated with mild/moderate head injuries in our review of literature: maxillofacial injuries, chest injuries, cervical spine injuries, and abdominopelvic trauma.

\section{Maxillofacial Injuries}

Generally, across all studies, the age group 15-44years is more vulnerable to having maxillofacial Injuries [19]. This result is similar to the study conducted by Yusuf et al, and this is mainly because this is the most active age group [5]. Road traffic accidents are the commonest causes and are commonly associated with motorcycle riders that do not wear helmets because the maxillofacial bones are prominent [19]. In a research of 859 patients with head injury, maxillofacial injuries accounted for $17.3 \%$ of the 227 patients $(39.7 \%)$ that had injuries associated with mild/moderate head injuries [19].

A cross-sectional study of 60 patients conducted by Hasnat et al. showed a high male to female ratio (7.57:1) [20]. This is similar to a study conducted in India, with a male to female ratio of 8.09:1 [21]. This indicates that males are more prone to having maxillofacial injuries related to head injuries, and [20] stated that it could be attributed to the familial setting in some societies-where men are usually the breadwinners. Also, males engage in riskier behaviors, like riding motorcycles and hanging on the side of the bus [20]. In another study of 360 patients by Shahzad et al, first riders $(65 \%)$ sustain head injuries more often than 2 nd riders. It also showed that facial injury was usually a major injury [22], which is in line with another study, where facial injury was also considered one of the commonest among patients involved in RTAs [23].

In a retrospective study of the patterns of maxillofacial fractures in 859 patients with a traumatic head injury, $70.15 \%$ of patients had mild traumatic brain injury [24]. Of the maxillofacial injuries, maxilla bone fractures were most common, occurring in $33.9 \%$ of patients, and these fractures were associated with the coronoid process of the mandible (fracture), Le fort fracture type II and type III. Moderate head Injuries were only associated with fractures of the coronoid process of the mandible [24]. Use of helmets in motorcycle riders was generally found to reduce the severity of head Injuries, hence maxillofacial injuries too. The time of arrival at the hospital was also important in eventual outcomes $[19,24]$.

\section{Chest Injuries}

According to a retrospective study on chest injuries associated with head injuries, by Mezue et al, data from medical records, operative notes and radiological findings of 30 patients admitted for head injury who had associated significant chest wall and intrathoracic injuries showed that about $46.7 \%$ suffered more than one type of chest injury and/or in more than one location [25]. The male to female ratio was $3: 1$, and these chest injuries were more common between 30-50 years [25]. Pneumothorax was found to be the most common intra-thoracic injury (33.3\%), followed by hemothorax (30\%), hemopneumothorax was seen in $13.3 \%$ of cases with major vessel damage in half of such. Chest wall (CW) lacerations occurred in $28.2 \%$, CW penetration in $7.6 \%$, rib fractures in $53.9 \%$, thoracic spinal fractures in $10.3 \%$ with associated $\mathrm{CW}$ injury in a quarter of such cases, flail chest from blunt trauma in $10.3 \%$ with an underlying pulmonary contusion in half of such cases [25].

The commonest cause of these injuries is road traffic accidents (60.0\%), which is similar to the study by Raza et al. with larger sample size and wider inclusion criteria- all the associated chest traumas were secondary to road traffic accidents [19]. Other causes include; gunshot injury (10.0\%), assault (13.3\%), iatrogenic (during ventilation) $(6.7 \%)$, falls $(10.0 \%)$ [25].

\section{Cervical Injuries}

In the last 50 years, the average annual incidence of concomitant TBI and spinal cord injuries has witnessed a significant increase and the most frequently involved area in the cervical spine is usually between the occiput and the $\mathrm{C} 3$ region $[26,27]$. Trauma patients with known head injury are shown to have simultaneous cervical spine injury in $4-8 \%$ of the cases $[28,29]$.

In a retrospective study of 358 patients, the percentage of males to females was $4.3: 1$, and the age ranged from 5 to 60 years [30]. Also, $63 \%$ of the patient population presented with loss of consciousness, while aphasia and quadriplegia were present in $9 \%$ and $27 \%$ of the patients, respectively. Other symptoms were gait disturbance, bleeding from the ear, urinary, and fecal incontinence [30]. 
In a prospective cohort study of 53 children less than 3 years with a head injury, $15.1 \%$ of the children had cervical spine injuries [31]. Also, a study of cervical injuries among children with non-motor vehicle crashassociated head injury, on use of advanced cervical imaging (Computed Tomography scan or Magnetic Resonance Imaging), showed abnormal findings such as vertebral injuries (fractures, dislocations, other), extra-axial spinal hemorrhages (subdural, epidural, subarachnoid, unspecified), cord injuries, and ligamentous injuries, and soft tissue injuries with associated hemorrhage [32].

\section{Abdomino-Pelvic Injuries}

In a study of 557 patients with traumatic brain injury, only $2.6 \%$ had an associated abdominopelvic injury [19], which is a relatively low percentage compared to other injuries associated with mild/moderate head injuries, in the study. According to Raza et al., high-grade head injury with GCS of 3-8 was often accompanied by abdominal injuries than low-grade head injury [33].

\section{Treatment and Rehabilitation Services}

Treatment for associated injuries in head-injured patients depends on the severity of the injury. Before treatment, patients are triaged and resuscitated. Subsequently, treatment is administered based on the severity of the injury [34]. Depending on the triage, it may be necessary to institute treatment immediately in the emergency room, while other patients may need to be admitted to the wards for treatment, and in fact, some require intensive care [34].

Based on the indication for surgery, patients can be broadly grouped as surgical and non-surgical patients. Associated injuries in head-injured patients requiring surgical management include traumatic injuries to the maxillofacial region; chest injuries such as hemothorax, rib fractures; injuries to the cervical region such as cervical fractures, transection of the cervical spinalcord and penetrating intra-abdominal injuries $[25,30,34,35]$.

Patients with maxillofacial injuries are required to be under neurosurgical observation and routine follow up [36]. A common problem in these patients is the compromise of the airway [36]. The airway should be stabilized through the administration of oxygen at 15 liters per minute and jaw thrust. Oropharyngeal and laryngeal mask airways should be used for resuscitation by highly skilled medical personnel when indicated [36].
Fracture to the facial and cranial bones can cause cerebrospinal fluid to leak out [36]. This can be managed conservatively by elevating the head 35 to 45 degrees and advising patients to avoid activities that can raise the intracranial pressure [36]. A lumbar drain should be inserted in the case where the leak persists after 72 hours. Surgery is indicated if the leak continues after 8 days [36].

Patients with minor injuries such as scalp lacerations are treated via suturing of lacerations and wound care after which they were observed and discharged [34] [37]. Patients with maxillofacial trauma can sustain severe cranial injuries and would benefit from management in the Intensive Care Unit where continuous vital signs and intensive monitoring are carried out[37]. Other forms of management beneficial to these patients include the prevention of edema and nasogastric tube feeding to avoid aspiration [37].

Associated chest injuries in patients pose a challenge in the management of head injury [25]. Splinting of fracture with the administration of analgesics suffices for a simple rib fracture. However, multiple rib fractures would require admission and monitoring to prevent respiratory failure [25]. Patients with flail chest, as a result of multiple rib fractures, will benefit from ventilation, though not always [25]. Two common intra-thoracic injuries, hemopneumothorax and pneumothorax, can be treated via tube thoracostomy. Some of these patients would require a thoracotomy, therefore, should be treated as such. Where tube thoracostomy cannot be performed, a needle thoracostomy is indicated in patients with an ominous tension pneumothorax [25].

In head-injured patients with intra-abdominal injury, laparotomy should be done without delay if the head injury does not put the patient in a terminal condition [38]. Generally, neurosurgical procedures and abdominal surgery can be done simultaneously provided the blood volume and respiratory status are satisfactory, and the neurosurgical procedure would not take several hours to complete. A head injury should not be considered an absolute contraindication to laparotomy [38].

Patients who have cervical injuries can be managed with skull traction and either hard or soft neck collar, as indicated [30]. Those with mild injuries are symptomatically managed, observed, and subsequently discharged. Also, rising evidence suggests that progesterone has neuroprotective effects in patients 
Odeyemi et al.

with both traumatic brain injury and cervical injury [30].

\section{Treatment Outcomes}

Patients with traumatic brain injuries and other associated injuries can gain full recovery and return to pre-morbid state after treatment. However, this is most times not the case as the majority of patients develop a varying manner of complications ranging from depressed mentation, cognitive, memory, focal or diffuse neurological deficit to, in some cases, death $[25,39,40]$. This outcome is largely dependent on several factors some of which are patients, physician, or facility dependent. Whereas patient with associated injuries to the lower extremities may do excellently and with good treatment outcomes, those with injuries involving the head and neck, thoracic regions are more likely to develop complications even after adequate treatment $[5,20]$. There was significant mortality among patients with chest injuries with associated head injuries with concurrent injuries to the great vessels.

Low GCS was found to be predictive of worst outcome in a study done by Julio Koboi et al. [30]. This finding was also corroborated by Patil et al and Alnaami et al. who documented that low GCS, advanced age, severity, and mechanism of injury, as well as spinal cord involvement, were significant in determining the outcome of patients with traumatic brain injury [41] [42]. However, Val da et al in his study found no association between admission GCS with poor outcomes [39]. Injuries located higher up in the spine are especially associated with high odds of mortality given the already established possible reasons- they play a great role in the maintenance of the cardiorespiratory functions. This pattern was also documented by Alnaami et al. [42].

Early radiological investigations, preferably CT and surgical interventions in patients with TBI and apparent indication for them were associated with good treatment outcomes and shortens periods of hospital stay contrary to those who were unable to access such interventions [5, 15,43].

The time between injury and presentation to the hospital, Injury Severity Score (ISS) are predictive of the outcome of patients with traumatic brain injury $[25,39,44]$. Whereas, there is no evidence to ascertain a different outcome in the pediatric age group, patients with early surgical interventions had a great outcome. Presence of other co-morbidities, intracranial hemorrhage, raised intracranial pressure, altered sensorium is associated with poor outcomes $[5,30,45,46]$.

\section{CONCLUSION}

Traumatic brain injury is a global and public health problem, which in the coming years, might be the leading cause of death in Africa. High incidence is found among the adolescent and the adult age group and gender-wise, it is common among the males of the same age group. The pattern of associated injuries with traumatic brain injury largely determines the outcome of the patient, however, prompt triaging, resuscitation, and physician examination are key to the right choice of intervention and ultimately leads to good patient care and a better outcome. Also, early investigation and prompt intervention were associated with a good outcome.

Finally, although fall is the commonest etiology in the elderly, road traffic accident remains the overall commonest cause of traumatic brain injury, especially in the underdeveloped countries, thus, stringent public road safety measures will be instrumental in reducing the incidence. Likewise, the provision of an ambulance system and standard healthcare facilities to manage patients with a traumatic brain injury can not be overemphasized.

Conflict of Interest: None to Declare

Source of funding: No funding

\section{REFERENCES}

1. Centre for Disease Control. Traumatic Brain Injury. Available at: https://www.cdc.gov/traumatic braininjury/index.html (Accessed: 12 July 2020).

2. Medscape June 2019. Traumatic Brain Injury (TBI)definition, epidemiology, pathophysio0logy. Available at: https://emedicine.medscape.com/ article/326510-overview\#a1 (Accessed: 12 July 2020).

3. Dewan MC, Rattani A, Gupta S, et al., Estimating the Global Incidence of Traumatic Brain Injury, J Neurosurg Volume 130; 1080-1097, April 2019. Published online April 27, 2018. doi: 10.3171/2017.10.JNS17352. 
4. McDonald SJ, Sun M, Agoston DV, Shultz SR. The effect of concomitant peripheral injury on Traumatic brain injury pathobiology and outcome. Journal of Neuroinflammation, 2016; 13(1): 90. doi: 10.1186/s12974-016-0555-1.

5. Yusuf AS, Odebode TO, Adeniran JO, Salaudeen AG, Adeleke NA, Alimi MF. Pattern and outcome of motorcyclists head injury in Ilorin, Nigeria. Niger J Basic Clin Sci 2014; 11: 80-4. doi: 10.4103/03318540.140340.

6. Pandey S, Singh K, Sharma V, Pandey D, Jha RP, Rai SK, Chauhan RS, Singh R. A prospective pilot study on serum cleaved tau protein as a neurological marker in severe traumatic brain injury. British Journal of Neurosurgery, 2017;31(3): 3356-363. doi: 10.1080/02688697.2017.1297378.

7. Punchak $M$, Abdelgadir J, Obiga O, Itait M, Najjuma JN, Haglund MM, Kitya D. Mechanism of Pediatric Traumatic Brain Injury in Southwestern Uganda: A Prospective Cohort of 100 patients. World Neurosurgery, 2018; 114: e396-e402. doi: 10.1016/j.wneu.2018.02.191.

8. WHO. Global Plan for the Decade of Action for Road Safety 2011-20, updated, 20. Available at: http://www.roadsafetyfund.org/TagSymbol/docu ments/global_plan_en.pdf (Accessed: 18 July 2020).

9. Wong JC, Linn KA, Shinohara RT, Mateen FJ. Traumatic brain injury in Africa in 2050: a modelling study, European Journal of Neurology 2016; 23: 382-6. doi: 10.1111/ene.12877.

10. Murray CJL, Lopez AD,editors. The Global Burde of Diseases, Injuries and Risk Factors in 1990 and projected in 2020. Boston: Harvard University Press; 1996.

11. Adeleye AO, Olowookere KG, Olayemi 00 . Clinicoepidemiological Profiles and Outcomes During First Hospital Admission of Head Injury Patients In Ikeja, Nigeria. Neuroepidemiology 2009; 32: 136-41. doi: 10.1159/000182821.

12. Khanbhai M, Lutomia MBL. Motorcycle Accident Injuries Seen at Kakamega Provincial Hospital in Kenya. East Cent. Afr. J. surg 2012;17:43-46.

13. Adeleye AO. Patterns of referrals of Head Injury to the University College Hospital, Ibadan. Annals of Ibadan Postgraduate Medicine, 2017; 15: 34-40.
14. Bangirana $P$, et al. Patterns of traumatic brain injury and six-month neuropsychological outcomes in Uganda. BMC Neurol. 2019; 19(1): 18. doi: 10.1186/s12883-019-1246-1.

15. Bedry T, Tadele $\mathrm{H}$. Pattern and Outcome of Pediatric Traumatic Brain Injury at Hawassa University Comprehensive Specialized Hospital. 2020: Article ID $1965231 . \quad$ doi: 10.1155/2020/1965231.

16. Boniface R, Lugazia ER, Ntungi AM, Kiloloma 0 . Management and outcome of traumatic brain injury patients at Muhimbili Orthopaedic Institute Dar es Salaam, Tanzania. Pan Afr Med J. 2017; 26: 140. doi: 10.11604/pamj.2017.26.140.10345.

17. Emejulu JKC, Isiguzo CM, Agbasoga CE, Ogbuagu $\mathrm{CN}$. Traumatic Brain Injury in the Accident and Emergency Department of a Tertiary Hospital in Nigeria. East and Central African Journal of Surgery, 2010; 15(2): 28-38.

18. Atwa H, Abdallah NB, Abd H, Gawad E. Pattern and outcome of paediatric head injuries in the Suez Canal region: A follow-up study. J Egypt Public Health Assoc. 2017; 92(1): 11-7. doi: 10.21608/epx.2017.7004.

19. Raza S, Shahzad Y, Shafiq-ur-Rahman, Tassadaq A, Akhtar N. Pattern of Head Injury and Associated Injuries in Patients Presenting to the Neurosurgical Emergency. Journal of Rawalpindi Medical College (JRMC), 2018; 22(2): 120-3.

20. Hasnat A, Hoque AKM, Selim-Ul-Aza, Kamrujjaman M, Akhtar M. Pattern of Maxillofacial Trauma among Patients with Head Injuries. UpDCJ. 2017; 7(1): 14-20. doi: 10.3329/updcj.v7i1.33304.

21. Rajendra PB, Mathew TP, Agrawal A, Sabharawal $G$. Characteristics of associated trauma in patients with head injuries: An experience with 100 cases. J Trauma and Shock, 2009; 2(2): 89-94. doi: 10.4103/0974-2700.50742.

22. Shahzad Y, Arshad A, Akhtar N. Pattern of Head Injury and Recovery in First and Second Rider in Motorbike Accidents. Journal of Rawalpindi Medical College (JRMC); 2017; 21(1): 33-6.

23. Chaudhary A, Wasti H. Pattern and Severity of injuries in Patients Following Road Trafffic Accidents- A Medicolegal Aspects. Eastern Green Neurosurgery, 2020; 2(1):13-7. doi: 10.3126/egn.v2i1.27455. 
24. Chansanti $O$, Anusitviwat $Y$, Mongkornwong A. The patterns of maxillofacial fractures in traumatic head injury patients in Songklanagarind hospital: a retrospective study. 2016.2 doi: $10.21203 /$ rs.2.21190/v1

25. Mezue WC, Ndubuisi CA, Erechukwu UA, Ohaegbulam SC. Chest injuries associated with head injury. Niger J Surg 2012; 18: 8-12.

26. Hagen EM, Eide GE, Rekand T, et al. Traumatic spinal cord injury and concomitant brain injury: A cohort study. ActaᄀNeurol Scand. 2010; 122: 51-7. doi: $10.1111 /$ j.1600-0404.2010.01376.x.

27. Tian $\mathrm{H}-\mathrm{L}, \mathrm{Guo} \mathrm{Y}, \mathrm{Hu} \mathrm{J}$, et al. Clinical characterization of comatose patients with cervical spine injury and traumatic brain injury. J Trauma Acute Care Surg. 2009; 67(6): 1305- 10. doi: 10.1097/TA.0b013e31819db57c.

28. Holly LT, Kelly DF, Counelis GJ, et al. Cervical spine trauma associated with moderate and severe head injury: Incidence, risk factors, and injury characteristics. J Neurosurg Spine, 2002; 96(3): 285-91. doi: 10.3171/spi.2002.96.3.0285.

29. Paiva WS, Oliveira AM, Andrade AF, et al. Spinal cord injury and its association with blunt head trauma. Int J Gen Med. 2011; 4: 613-5. doi: 10.2147/IJGM.S15811.

30. Kiboi J, Omar A, Omar MA. Head Injury with Concurrent Cervical Spine Injury. Ann Afr Surg. 2019; 16(1): 11-5. doi: 10.4314/aas.v16i1.3.

31. Oh A, Sawvel M, Heaner D, et al. Changes in use of cervical spine magnetic resonance imaging for pediatric patients with nonaccidental trauma. J NeurosurgPediatr. 2017; 20(3): 271-7. PubMed: 28665242. doi: 10.3171/2017.2.PEDS16644.

32. Henry MK, French B, Feudtner C, Zonfrillo MR, Lindberg DM, Anderst JD, Berger RP \& Wood JN. Cervical Spine Imaging and Injuries in Young Children with Non-Motor Vehicle Crash-Associated Traumatic Brain Injury. PediatrEmerg Care; 2019: 1-14. doi: 10.1097/PEC.0000000000001455.

33. Park JC, Chang IB, Ahn JH, Kim JH, Oh JK, Song JH. Epidemiology and Risk Factors for Bicycle-Related Severe Head Injury: A single-centre experience. Korean J Neurotrauma. 2017 Oct; 13(2): 90-5. doi: 10.13004/kjnt.2017.13.2.90.
34. Usman B, Mohammed B. Head Injury in Maiduguri: An 18month Review. Bo Med J 2018;15(2):60-3. doi: 10.31173/bomj.bomj_106_15.

35. Raza S, Shahzad Y, Shafiq-ur-Rahman, Tassadaq A, Akhtar N. Pattern of Head Injury and Associated Injuries in Patients Presenting to the Neurosurgical Emergency. Journal of Rawalpindi Medical College (JRMC), 2018; 22(2): 120-3.

36. Choonthar MM, Raghothaman A, Prasad R, Pradeep S, Pandya K. Head Injury- A Maxillofacial Surgeon's Perspective. J Clin Diagn Res., 2016 Jan; 10(1): ZE01-ZE06. doi: 10.7860/JCDR/2016/16112.7122.

37. Chinda JY, Abubakar AM, Umaru H, Tahir C, Adamu $\mathrm{S}$, Wabada S. Epidemiology and management of head injury in paediatric age group in NorthEastern Nigeria. Afr J Paediatr Surg. 2013; 10: 35861. doi: 10.4103/0189-6725.125448.

38. Wilson CB. The Management of Abdominal Injuries in the Presence of Head Injury. The Western Journal of Medicine, 1969 Nov; 111(5): 343-6.

39. Van der Naalt J, Van Zomeren AH, Sluiter WJ, Minderhoud JM. One year outcome in mild to moderate head injury: the predictive value of acute injury characteristics related to complaints and return to work. Journal of Neurology, Neurosurgery \& Psychiatry, 1999 Feb 1; 66(2): 20713. doi: 10.1136/jnnp.66.2.207.

40. Yue JK, Upadhyayula PS, Avalos LN, Phelps RRL, Suen CG, Cage TA. Concussion and Mild-Traumatic Brain Injury in Rural Settings: Epidemiology and Specific Health Care Considerations. Journal of Neurosciences in Rural Practice. 2020 Jan; 11(01): 23-33. doi: $10.1055 / \mathrm{s}-0039-3402581$.

41. Patil S, Huda T, Jain SC, Pandya B, Narang R. Comparative study of pattern of head injury in a rural community hospital and a tertiary care hospital. Int Surg J. 2019 Nov 26; 6(12): 4272. doi: 10.18203/2349-2902.isj20195386.

42. Alnaami I, Alshehri S, Alghamdi S, Ogran M, Qasem A, Medawi A, et al. Patterns, Types, and Outcomes of Head Injury in Aseer Region, Kingdom of Saudi Arabia. Neuroscience Journal. 2019 Mar 7; 2019: 16. doi: $10.1155 / 2019 / 2782146$. 
43. Heydari F, Golban M, Majidinejad S. Traumatic Brain Injury in Older Adults Presenting to the Emergency Department: Epidemiology, Outcomes and Risk Factors Predicting the Prognosis. Advanced Journal of Emergency Medicine, 2019 Aug 19; 4(2): e19.

44. Roozenbeek B, Maas AIR, Menon DK. Changing patterns in the epidemiology of traumatic brain injury. Nat Rev Neurol. 2013 Apr; 9(4): 231-6. doi: 10.1038/nrneurol.2013.22.
45. Agrawal A, Agrawal CS, Kumar A, Lewis O, Malla G, Chalise P. Head Injury at a Tertiary Referral Centre in the Eastern Region of Nepal; ECAJS. 2009; 14.

46. Peeters W, van den Brande R, Polinder S, Brazinova A, Steyerberg EW, Lingsma HF, et al. Epidemiology of traumatic brain injury in Europe. Acta Neurochir. 2015 Oct;157(10):1683-96. doi: 10.1007/s00701-015-2512-7.

https://www.ejbms.net 